\title{
Endoscopic ultrasound findings and pathological features of pancreatic carcinoma in situ
}

\section{(ㄷ)(요 $\odot$}

\section{Authors}

Yoshihiro Izumi ${ }^{1}$, Keiji Hanada², Akihito Okazaki ${ }^{3}$, Tomoyuki Minami², Naomichi Hirano ${ }^{2}$, Juri Ikemoto ${ }^{4}$, Kozue Kanemitsu ${ }^{5}$, Koichi Nakadoi², Takayoshi Shishido², Yoshio Katamura², Seiji Onogawa², Hajime Amano², Fumiaki Hino $^{2}$, Hironobu Amano ${ }^{6}$, Shuji Yonehara?

\section{Institutions}

1 Department of Gastroenterology, Kumamoto General Hospital, Japan Community Health Care Organization, Kumamoto, Japan

2 Department of Gastroenterology, Onomichi General Hospital, Hiroshima Kosei Federation of Agricultural Cooperatives, Hiroshima, Japan

3 Department of Gastroenterology, Hiroshima Red Cross Hospital \& Atomic-bomb Survivors Hospital, Hiroshima, Japan

4 Department of Gastroenterology and Metabolism of Hiroshima University, Hiroshima, Japan

5 Department of Gastroenterology, Uwajima City Hospital, Uwajima, Japan

6 Department of Surgery, Onomichi General Hospital, Hiroshima Kosei Federation of Agricultural Cooperatives, Hiroshima, Japan

7 Department of Pathology, Onomichi General Hospital, Hiroshima Kosei Federation of Agricultural Cooperatives, Hiroshima, Japan

submitted 7.3.2018

accepted after revision $\quad 27.12 .2018$

\section{Bibliography}

DOI https://doi.org/10.1055/a-0839-4312 |

Endoscopy International Open 2019; 07: E585-E593

(c) Georg Thieme Verlag KG Stuttgart · New York ISSN 2364-3722

\section{Corresponding author}

Yoshihiro Izumi, Department of Gastroenterology, Kumamoto General Hospital, Japan Community Health Care Organization, 10-10 Tohricho, Yatsushiro, Kumamoto 8668660, Japan

Fax: +81-965-32-2772

y.izumi1213@gmail.com

\section{ABSTRACT}

Background and study aims Few studies have evaluated detection of pancreatic carcinoma in situ (PCIS). We evaluated findings of endoscopic ultrasound (EUS) and pathological features of PCIS.

Patients and methods We histopathologically studied 16 patients with PCIS following EUS. Diagnostic features evaluated retrospectively included stricture of the main pancreatic duct (MPD) on EUS, presence or absence of hypoechoic areas surrounding the MPD stricture on EUS, the noncancerous part (pancreas of background) on EUS and histopathology, and histological findings adjacent to the area of PCIS.

Results On EUS, stricture of the MPD was found in 15 patients $(93.8 \%)$. Hypoechoic areas surrounding the MPD stricture were observed in 9 patients $(56.3 \%)$, including three $(18.8 \%)$ with a 10 - to $11-\mathrm{mm}$ hypoechoic mass. EUS findings of the noncancerous part indicated chronic pancreatitis in six patients ( $37.5 \%)$, pancreatic fatty infiltration in seven (43.8\%), early chronic pancreatitis in two (12.5\%), and normal pancreas in one (6.3\%). Histological findings of the noncancerous part (proximal to the MPD stricture) indicated chronic pancreatitis in 13 patients (81.3\%) and pancreatic fatty infiltration in five patients $(31.3 \%)$. Histopathologically, subepithelial inflammatory cell infiltration and fibrosis were present in all 16 patients with PCIS.

Conclusions PCIS frequently causes localized changes in inflammation and fibrosis around the pancreatic duct. PCIS often accompanies chronic pancreatitis and pancreatic fatty infiltration in the background of the pancreas. EUS offers sufficient resolution to demonstrate pancreatic changes of PCIS. 


\section{Introduction}

Few studies have evaluated detection of pancreatic carcinoma in situ (PCIS). The number of patients with pancreatic cancer in Japan is increasing every year. According to vital statistics of the Ministry of Health, Labor, and Welfare, the number of pancreatic cancer-related deaths exceeded 30,000 for the first time in 2013 [1]. Furthermore, pancreatic cancer was reported to be the fourth leading cause of cancer-related deaths after lung, stomach, and colorectal cancer [1]. Rahib et al. [2] estimated that by 2030 , pancreatic cancer would be the second leading cause of cancer-related deaths in the United States. The actual reason for the increased death rate is difficulty in early diagnosis, and by the time the disease is diagnosed, it is often too late. Early diagnosis is critical for improving survival in these patients. In 2012, the Japan Pancreas Society reported outcomes of the pancreatic cancer registry, in which 5-year survival rates according to tumor size were $80.4 \%$ for 3 - to $10-\mathrm{mm}$ and $50 \%$ for 10 - to 20 -mm tumors. According to staging, the 5 year survival rates based on the Union for International Cancer Control classification were $85.8 \%$ for stage 0 and $68.7 \%$ for stage la disease [3]. To improve the prognosis of pancreatic cancer, early diagnosis of stage 0 or of $<10$-mm tumors is indispensable.

The 2013 Japanese clinical guidelines for pancreatic cancer emphasize detection of indirect findings, such as dilatation of the main pancreatic duct (MPD) and pancreatic cysts, for early diagnosis of pancreatic cancer [4]. Considering that no neoplastic lesions are delineated on abdominal ultrasonography or computed tomography examination, magnetic resonance cholangiopancreatography (MRCP) and endoscopic ultrasound (EUS) are recommended [4]. However, EUS findings of PCIS are not well characterized because very few reports have described PCIS in detail. At the Onomichi General Hospital, since 2007, a concerted effort has been made to diagnose pancreatic cancer early through cooperation between hospitals and clinics [5]. As a result of these efforts, a total of 16 cases of PCIS were detected over a period of 8 years. This study was conducted to evaluate the EUS findings and pathological features of PCIS.

\section{Patients and methods}

The current study was approved by the Institutional Review Board of the Onomichi General Hospital. We retrospectively analyzed 16 patients (mean age, 68.4 \pm 9.1 years; range, 52-84 years; male-to-female ratio, 9:7) undergoing pancreatectomy and diagnosed with PCIS at the Onomichi General Hospital between January 2007 and April 2015.

PanIN occurs from the pancreatic duct epithelium and is a noninvasive intraepithelial neoplastic lesion with a papillary or flat morphology observed at the microscopic level. PanIN is composed of cylindrical to cubic cells with varying amounts of mucus that exhibiting varying degrees of cellular and structural atypia. PanIN is usually found in pancreatic ducts with diameters less than $5 \mathrm{~mm}$ [6]. It is classified as PanIN-1 to 3, and PCIS in this paper is defined pathologically as a lesion with atypia equivalent to PanIN-3. PanIN is considered to be an important lesion as a precursor to invasive ductal carcinoma. According to the most recent Baltimore pathology classification, PCIS is defined as a lesion equivalent to high-grade PanIN [7].

An intraepithelial lesion corresponding to PanIN-3 was found in the MPD or the pancreatic duct branches surrounding the MPD stricture. The maximum diameter of the progress range of six cases of PCIS described in pathological diagnosis was 2 to $20 \mathrm{~mm}$ (median $10.5 \mathrm{~mm}$ ). In 12 of 16 cases, adenocarcinoma was detected by preoperative pancreatic juice cytology, and surgery was performed by diagnosis of pancreatic cancer. Because adenocarcinoma was detected by pancreatic juice cytology, endoscopic ultrasound-guided fine-needle aspiration (EUS-FNA) was not a requirement. In three cases, malignant cells were not recognized by preoperative pancreatic juice cytology, but malignancy could not be ruled out on diagnostic imaging, and surgery was performed for a diagnosis of suspected pancreatic cancer. In two of these three cases, EUS-FNA was not required because hypoechoic areas surrounding the MPD stricture were observed and fibrosis by PCIS was assumed. 1 case had a hypoechoic mass and EUS-FNA was also considered, but because of coexisting distal cholangiocarcinoma, EUS-FNA was omitted and surgery was performed. In one case, surgery was performed for diagnosis of distal cholangiocarcinoma, and PCIS was incidentally observed in the pancreatic cut end margin of the resected specimen. Only in that case, MPD stricture and dilatation were not observed. All 16 cases in this paper are PCIS and invasive pancreatic duct carcinoma and intraductal papillary mucinous neoplasms (IPMN) were not included.

MPD dilatation on the distal side of the MPD stricture was defined as a diameter of $3 \mathrm{~mm}$ or more, and larger than the MPD diameter on the proximal side of the MPD stricture. The key findings that led to early diagnosis were dilatation of the MPD in 10 patients, dilatation of the MPD plus pancreatic cyst in five, and incidental diagnosis in one. The affected sites were the pancreatic head in four patients, pancreatic body in 11, and pancreatic tail in one. The lesions were localized in the MPD plus pancreatic duct branches in 10 patients, MPD in four, and pancreatic duct branches in two. MPD stricture was confirmed on MRCP or endoscopic retrograde cholangiopancreatography (ERCP) in 15 patients (93.8\%). EUS was preoperatively performed in all patients. The study subjects were examined in terms of stricture of the MPD on EUS, presence or absence of hypoechoic areas surrounding the MPD stricture on EUS, the noncancerous part (pancreas of background) on EUS and histopathology, and histological findings adjacent to the area of PCIS.

EUS findings for the noncancerous part were evaluated in accordance with the Rosemont classification [8] and the 2009 Japanese Clinical Diagnostic Criteria for Chronic Pancreatitis [9]. In 2009, Catalano et al. [8] proposed the new EUS-based diagnostic criteria for chronic pancreatitis (Rosemont classification). In Japan, this proposal was accepted and clinical diagnostic criteria for early chronic pancreatitis were included in the 2009 Japanese clinical diagnostic criteria for chronic pancreatitis [9] as the first in the world. According to the diagnostic criteria, the four markers of pancreatic parenchyma disorder due to pancreatitis or risk factors for pancreatitis are: 1 ) repeated and 
inordinate abdominal pain; 2) abnormality (serum or urine) of pancreatic enzyme levels; 3 ) reduced pancreatic exocrine function; and 4) continuous heavy drinking $>80 \mathrm{~g} /$ day. Early chronic pancreatitis was defined as a patient who had two or more of the four markers and a slightly abnormal finding of the pancreatic parenchyma or pancreatic duct suggesting early lesions of chronic pancreatitis on EUS or ERCP. For EUS diagnosis, seven findings are relevant: 1) lobularity with honeycombing; 2) lobularity without honeycombing; 3 ) hyperechoic foci without shadowing; 4) stranding; 50 cysts; 6 ) dilated side branches; and 7) hyperechoic main pancreatic duct margin. When two or more items including 1 and 4 were recognized, an image was deemed to fulfill the diagnosis of early chronic pancreatitis. In 2016, Whitcomb et al. [10] announced a "new mechanistic definition" of chronic pancreatitis, taking into account the onset mechanism of pancreatitis. The proposed definition said, "Chronic pancreatitis is a pathologic fibro-inflammatory syndrome of the pancreas in individuals with genetic, environmental and/or other risk factors who develop persistent pathologic responses to parenchymal injury or stress." In the new definition, a conceptual model of five stages also was proposed, from "at risk" to "AP-RAP, acute pancreatitis and recurrent acute pancreatitis," "early CP, chronic pancreatitis," and "established CP," to "end stage $C P$ ". "Early $C P$ " is the preliminary stage of "established CP" and is regarded as a condition that can be brought into remission. "Established CP" is a stage where obvious functional abnormalities are confirmed in two or more systems immune, exocrine, and endocrine - and pathologic pain and metaplasia are present because of persistent parenchymal injury or stress added to "early CP." "End stage CP" is a stage where dysfunctions are recognized in two or more systems. Pancreatic fatty infiltration was determined by pancreatic parenchymal hyperechoic findings with deep echo attenuation in EUS findings of the noncancerous part. It is a well-known fact that in cases with MPD stricture, obstructive pancreatitis occurs on the distal side of the stricture. Therefore, pathological findings of the noncancerous part were proximally evaluated from the MPD stricture to exclude the effects of obstructive pancreatitis. Pathological findings of chronic pancreatitis were examined according to the characteristic histological findings included in the 2009 Japanese Clinical Diagnostic Criteria for Chronic Pancreatitis [9]. Definitive diagnosis of chronic pancreatitis was based on observation of fibrosis and loss of pancreatic parenchyma. Pancreatic fibrosis was primarily observed interlobularly with a nodular small lobe, which in other words, appears like cirrhosis. Criteria for definitive diagnosis of chronic pancreatitis include loss of pancreatic parenchyma with interlobular fibrosis or interlobular and intralobular fibrosis. The Olympus EU-ME1, EU-ME2, or Hitachi-Aloka Medical ProSound Alpha 10 instrument was used as the measurement device, and the Olympus GF-UE260-AL5 or GF-UM2000 scope was used for endoscopy.

\section{Results}

Clinicopathological characteristics of the 16 subjects are shown in $>$ Table 1, > Table 2, and $>$ Table 3.

An MPD stricture was identified on EUS in 15 patients (93.8\%). One such patient is shown in - Fig. 1. In one patient, the MPD stricture could not be identified on EUS; identification of the same stricture was also difficult on MRCP. PCIS in this patient was incidentally diagnosed on pathological examination of the resected pancreatic specimen.

On EUS, the hypoechoic areas surrounding the MPD stricture were observed in nine patients $(56.3 \%)$, including three (18.8\%) with a hypoechoic mass $(10-11 \mathrm{~mm})$. One such patient is shown in $>$ Fig. 2.

EUS findings on the noncancerous part indicated chronic pancreatitis in six patients (37.5\%), fatty infiltration in seven (43.8\%), early chronic pancreatitis [7] in two (12.5\%), and normal pancreas in one (6.3\%). Histopathological examination of the noncancerous part (proximal to the MPD stricture) revealed characteristic findings of chronic pancreatitis in 13 patients $(81.3 \%)$, including eight with severe inflammation in the pancreatic parenchyma distal to the stricture) and pancreatic fatty infiltration in five $(31.3 \%)$. Concurrent IPMN was observed in the resected and residual pancreas in five patients (31.3\%), all of whom had branch duct IPMN. Concurrent pancreatic intraepithelial neoplasia (PanIN) not in continuity with the primary lesion of the resected pancreas was observed in 12 patients (75\%). Two patients who fulfilled the Japanese Clinical Diagnostic Criteria for early chronic pancreatitis [9] (Cases 12 and 13) were relatively young women with no history of regular alcohol intake, and did not show characteristic histological findings of

\begin{tabular}{l|c|}
$\begin{array}{l}\text { Table } 1 \text { Study group }(n=16) \text {, including the characteristics of pan- } \\
\text { creatic carcinoma in situ. }\end{array}$ & $68.4 \pm 9.1(52-84)$ years \\
\hline \begin{tabular}{l} 
Age, mean \pm SD \\
\hline Sex ratio (male/female)
\end{tabular} & $9 / 7$ \\
\hline Opportunity & 5 \\
\hline MPD dilatation & 1 \\
\hline MPD dilatation + cysts & 4 \\
\hline Other & 11 \\
\hline Region & 1 \\
\hline Head & \\
\hline Body & 10 \\
\hline Tail & 4 \\
\hline Localization & 2 \\
\hline MPD + Branch & \\
\hline MPD & \\
\hline Branch & Number of cases is indicated unless otherwise indicated. SD, standard de- \\
\hline viation; MPD, main pancreatic duct. & \\
\hline
\end{tabular}


- Table 2 Clinical information on patients included in the study.

\begin{tabular}{|c|c|c|c|c|c|c|c|}
\hline Case & Age & Sex & Opportunity & Region & Localization & $\begin{array}{l}\text { EUS findings } \\
\text { MPD stricture/ } \\
\text { Hypoechoic (size) }\end{array}$ & $\begin{array}{l}\text { Pathological findings } \\
\text { Noncancerous part/ } \\
\text { Periphery of the lesion }\end{array}$ \\
\hline 1 & 73 & $\mathrm{~F}$ & MPD dilatation & Body & Branch & $+1+$ & $\mathrm{CP} /$ Inflammation and fibrosis \\
\hline 2 & 70 & M & MPD dilatation & Body & MPD + Branch & $+1+$ & $\mathrm{CP} /$ Inflammation and fibrosis \\
\hline 3 & 78 & $\mathrm{~F}$ & MPD dilatation & Body & MPD & $+1+$ & $\mathrm{CP} /$ Inflammation and fibrosis \\
\hline 4 & 61 & M & MPD dilatation & Body & MPD & $+1-$ & $\mathrm{CP} /$ Inflammation and fibrosis \\
\hline 5 & 82 & M & MPD dilatation + Cysts & Head & Branch & $+1+$ & $\mathrm{CP} /$ Inflammation and fibrosis \\
\hline 6 & 84 & $\mathrm{~F}$ & MPD dilatation & Body & MPD + Branch & $+1+$ & $\mathrm{CP} /$ Inflammation and fibrosis \\
\hline 7 & 75 & M & MPD dilatation + Cysts & Body & MPD + Branch & $+1-$ & $\mathrm{CP} /$ Inflammation and fibrosis \\
\hline 8 & 65 & $\mathrm{~F}$ & MPD dilatation & Body & MPD + Branch & $+/+(10 \mathrm{~mm})$ & $\mathrm{CP} /$ Inflammation and fibrosis \\
\hline 9 & 63 & $\mathrm{~F}$ & MPD dilatation + Cysts & Body & MPD + Branch & $+1-$ & normal/Inflammation and fibrosis \\
\hline 10 & 66 & M & MPD dilatation + Cysts & Head & MPD + Branch & $+/+(11 \mathrm{~mm})$ & $\mathrm{CP} /$ Inflammation and fibrosis \\
\hline 11 & 58 & M & MPD dilatation + Cysts & Tail & MPD + Branch & $+1-$ & $\mathrm{CP} /$ Inflammation and fibrosis \\
\hline 12 & 52 & $\mathrm{~F}$ & MPD dilatation & Body & MPD + Branch & $+/+(10 \mathrm{~mm})$ & normal/Inflammation and fibrosis \\
\hline 13 & 59 & $\mathrm{~F}$ & MPD dilatation & Body & MPD & $+1-$ & normal/Inflammation and fibrosis \\
\hline 14 & 76 & M & MPD dilatation & Head & MPD + Branch & $+1+$ & $\mathrm{CP} /$ Inflammation and fibrosis \\
\hline 15 & 69 & M & Other (accidental) & Head & MPD & $-1-$ & $\mathrm{CP} /$ Inflammation and fibrosis \\
\hline 16 & 64 & M & MPD dilatation & Body & MPD + Branch & $+1-$ & $\mathrm{CP} /$ Inflammation and fibrosis \\
\hline
\end{tabular}

chronic pancreatitis, but only showed mild sporadic fat droplets. Cases of chronic pancreatitis, pancreatic fatty infiltration, and early chronic pancreatitis are shown in ₹ Fig. 3 as pathological findings of noncancerous part, respectively $\nabla$ Fig. 3 a shows chronic pancreatitis (Case 8), - Fig. 3b shows fatty infiltration (Case 7 ), and $\triangleright$ Fig. 3 c shows early chronic pancreatitis (Case 13).

Perilesional interstitial inflammatory cell infiltration and fibrosis were observed in all 16 patients. One such patient is shown in > Fig. 4.

\section{Discussion}

In the 1950 s, a hypothesis was proposed that pancreatic cancer progressively develops from hyperplasia of the pancreatic duct epithelium after development into atypical lesions [11]. In 2000, Hruban et al. [12] proposed PanIN, a multistep model of the carcinogenesis of pancreatic cancer. Thereafter, molecular pathological examinations and analysis of genetically modified mice demonstrated the precancerous nature of PanIN. Malignant transformation in the pancreas is caused by accumulation of genetic abnormalities in genes, such as in KRAS, CDKN2A, TP53, and SMAD4, with a stepwise transition from PanIN-1A to PanIN-3, corresponding to carcinoma in situ and progressing to invasive cancer. Pancreatic cancer is well-known to be accompanied by severe fibrosis around the tumor cells and desmoplastic reaction (DR). In 2004, pancreatic stellate cells, which contribute to fibrosis in chronic pancreatitis, were demonstrated to produce an extracellular matrix of cancer stroma [13]. Interaction between pancreatic cancer and DR has also been explained at the molecular level, in which partial changes are observed at the stage of PanIN and IPMN without invasive cancer. Furthermore, Yachida et al. [14] examined pancreatic cancer using autopsy cases; they estimated a mean of $11.7 \pm$ 3.1 years from initial appearance of the genetic abnormality to development of invasive cancer; $6.8 \pm 3.4$ years from the stage of invasive cancer to development of metastatic potential, and $2.7 \pm 1.2$ years from acquiring metastatic potential until actual metastasis. We believe that development of diagnostic interventions for use during the period between carcinoma in situ and development of invasive cancer could help improve the likelihood of early diagnosis of pancreatic cancer. The clinical significance for the reader of Endoscopy International Open is to identify early pancreatic cancer by understanding imaging and pathological findings for PCIS and carrying out appropriate diagnostic imaging.

The regions were the pancreatic head in four patients, pancreatic body in 11 , and pancreatic tail in one ( $\downarrow$ Table 1$)$. Most cases of PCIS were identified through indirect means, such as dilatation of the MPD and pancreatic cysts. Because it is difficult to make such findings in the pancreatic head and tail on abdominal US, lesions in the body of the pancreas may be overrepresented in this study. 
- Table 3 Pathological findings of the patients included in the study.

\begin{tabular}{|c|c|c|c|c|c|c|c|c|}
\hline \multirow[t]{2}{*}{ Case } & \multirow[t]{2}{*}{ Age } & \multirow[t]{2}{*}{ Sex } & \multicolumn{2}{|l|}{ EUS findings } & \multicolumn{4}{|c|}{ Pathological findings } \\
\hline & & & $\begin{array}{l}\text { MPD stricture/ } \\
\text { Hypoechoic } \\
\text { (size) }\end{array}$ & $\begin{array}{l}\text { Noncancerous } \\
\text { part }\end{array}$ & $\begin{array}{l}\text { Noncancerous } \\
\text { part }\end{array}$ & Notices & $\begin{array}{l}\text { Periphery of } \\
\text { the lesion }\end{array}$ & Findings \\
\hline 1 & 73 & $\mathrm{~F}$ & $+1+$ & $\mathrm{FI}$ & $\mathrm{CP}$ & & $\begin{array}{l}\text { Inflammation } \\
\text { and fibrosis }\end{array}$ & \\
\hline 2 & 70 & M & $+1+$ & $\mathrm{CP}$ & $\mathrm{CP}$ & & $\begin{array}{l}\text { Inflammation } \\
\text { and fibrosis }\end{array}$ & \\
\hline 3 & 78 & $\mathrm{~F}$ & $+1+$ & $\mathrm{FI}$ & $\mathrm{CP}$ & & $\begin{array}{l}\text { Inflammation } \\
\text { and fibrosis }\end{array}$ & \\
\hline 4 & 61 & M & $+1-$ & $\mathrm{FI}$ & $\mathrm{CP}$ & $\mathrm{Fl}$ & $\begin{array}{l}\text { Inflammation } \\
\text { and fibrosis }\end{array}$ & \\
\hline 5 & 82 & M & $+1+$ & $\mathrm{CP}$ & $\mathrm{CP}$ & & $\begin{array}{l}\text { Inflammation } \\
\text { and fibrosis }\end{array}$ & \\
\hline 6 & 84 & $\mathrm{~F}$ & $+1+$ & $\mathrm{CP}$ & $\mathrm{CP}$ & & $\begin{array}{l}\text { Inflammation } \\
\text { and fibrosis }\end{array}$ & \\
\hline 7 & 75 & M & $+1-$ & $\mathrm{FI}$ & $\mathrm{CP}$ & $\mathrm{Fl}$ (severe) & $\begin{array}{l}\text { Inflammation } \\
\text { and fibrosis }\end{array}$ & \\
\hline 8 & 65 & $\mathrm{~F}$ & $+/+(10 \mathrm{~mm})$ & $\mathrm{FI}$ & $\mathrm{CP}$ & $\mathrm{FI}$ & $\begin{array}{l}\text { Inflammation } \\
\text { and fibrosis }\end{array}$ & \\
\hline 9 & 63 & $\mathrm{~F}$ & $+1-$ & normal & normal & & $\begin{array}{l}\text { Inflammation } \\
\text { and fibrosis }\end{array}$ & Mild fibrosis \\
\hline 10 & 66 & M & $+/+(11 \mathrm{~mm})$ & $\mathrm{CP}$ & $\mathrm{CP}$ & & $\begin{array}{l}\text { Inflammation } \\
\text { and fibrosis }\end{array}$ & \\
\hline 11 & 58 & M & $+1-$ & $\mathrm{FI}$ & $\mathrm{CP}$ & $\mathrm{Fl}$ (severe) & $\begin{array}{l}\text { Inflammation } \\
\text { and fibrosis }\end{array}$ & Mild fibrosis \\
\hline 12 & 52 & $\mathrm{~F}$ & $+/+(10 \mathrm{~mm})$ & ECP & normal & $\begin{array}{l}\text { Sporadic fat } \\
\text { droplets }\end{array}$ & $\begin{array}{l}\text { Inflammation } \\
\text { and fibrosis }\end{array}$ & Severe fibrosis \\
\hline 13 & 59 & $\mathrm{~F}$ & $+1-$ & ECP & normal & $\begin{array}{l}\text { Sporadic fat } \\
\text { droplets }\end{array}$ & $\begin{array}{l}\text { Inflammation } \\
\text { and fibrosis }\end{array}$ & \\
\hline 14 & 76 & M & $+1+$ & $\mathrm{CP}$ & $\mathrm{CP}$ & & $\begin{array}{l}\text { Inflammation } \\
\text { and fibrosis }\end{array}$ & \\
\hline 15 & 69 & M & $-1-$ & $\mathrm{CP}$ & $\mathrm{CP}$ & & $\begin{array}{l}\text { Inflammation } \\
\text { and fibrosis }\end{array}$ & \\
\hline 16 & 64 & M & $+1-$ & $\mathrm{FI}$ & $\mathrm{CP}$ & $\mathrm{FI}$ & $\begin{array}{l}\text { Inflammation } \\
\text { and fibrosis }\end{array}$ & \\
\hline
\end{tabular}

MPD, main pancreatic duct; FI, fatty infiltration; CP, chronic pancreatitis; ECP, early chronic pancreatitis.

Del Chiaro $\mathrm{M}$ et al. [15] reported that during a median follow-up of approximately 1 year, pancreatic lesions were detected in $40 \%$ of patients, of whom five underwent surgery, and a noninvasive magnetic resonance imaging (MRI)-based screening protocol in individuals at risk seems to be effective. Harinck et al. [16] reported that EUS and/or MRI detected clinically relevant pancreatic lesions in $6 \%$ of high-risk individuals, and both imaging techniques were complementary rather than interchangeable. Canto $\mathrm{Ml}$ et al. [17] reported that screening of asymptomatic high-risk individuals frequently detects small pancreatic cysts, including curable, noninvasive high-grade neoplasms. EUS and MRI detect pancreatic lesions better than does CT. Verna EC et al. [18] reported that pancreatic cancer screening for high-risk patients with a comprehensive strategy of imaging and genetics is effective and identifies curable neoplasms that can be resected. Yasuda I et al. [19] reported that EUS is strongly recommended for early detection of small pancreatic cancer in patients in whom dilation of the main pancreatic duct was detected in previous imaging tests, with or without increase of pancreatic enzymes or tumor markers. Kamata $\mathrm{K}$ et al. [20] reported that IPMN-concomitant pancreatic ductal adenocarcinomas are quite often found at diagnosis and during follow-up, and EUS examination of the whole pancreas plays an important role in management of IPMNs as it allows early de- 

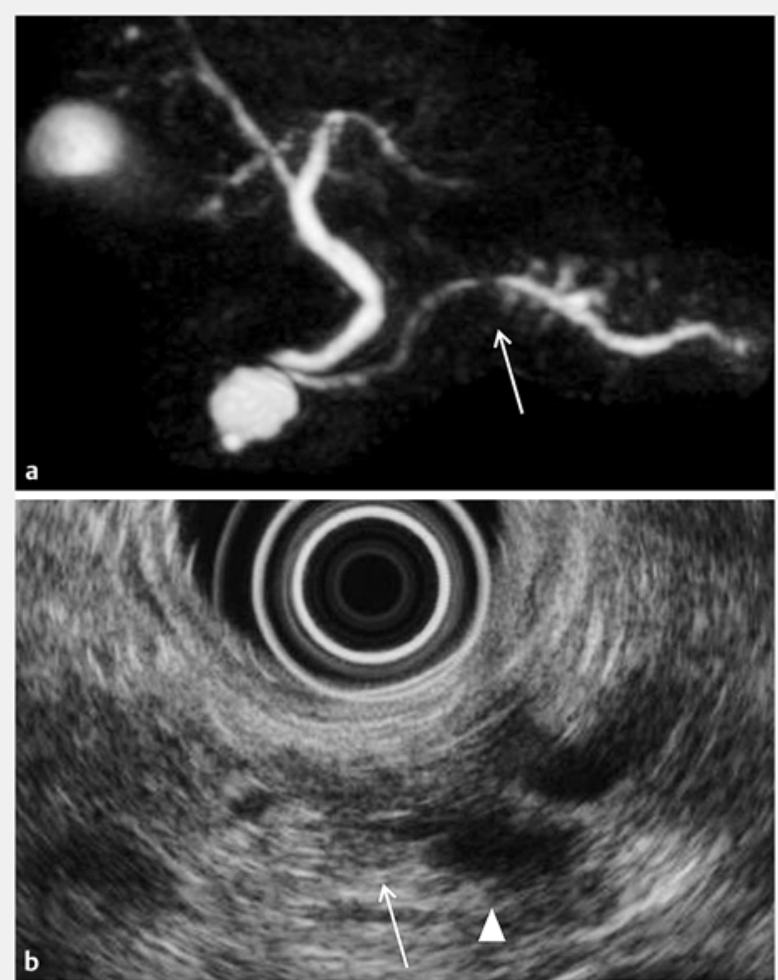

- Fig. 1 A 73-year-old female with PCIS and branch duct IPMN (Case 1). MRCP a and EUS b revealed MPD stricture (arrow) and MPD dilatation (triangle). PCIS, pancreatic carcinoma in situ; MRCP, magnetic resonance cholangiopancreatography; EUS, endoscopic ultrasonography; MPD, main pancreatic duct.

tection of these small, invasive carcinomas. Reports on usefulness of MRCP and EUS for early diagnosis of pancreatic cancer are scattered, but there are very few reports on PCIS imaging diagnosis. In diagnostic imaging, PCIS itself cannot be drawn, so it is necessary to estimate from the MPD stricture and surrounding tissue change by PCIS. It is important for image diagnosis to capture localized MPD stricture and a surrounding fibrotic area caused by PCIS. Noninvasive MRCP is useful for screening for MPD stricture, and EUS with high resolution is effective for evaluating the surrounding fibrotic area.

A localized MPD stricture was frequently observed on the image finding for PCIS. Pathologically, several cases in our study exhibited localized inflammation and fibrosis in the interstitial tissue around the pancreatic ducts in which the PCIS was located. In our report concerning 16 patients with PCIS, most patients had a localized MPD stricture (15/16, 93.8\%) ( $>$ Table 2). Evaluation by MRCP revealed dilatation of the MPD distal to the stricture in nine of 16 patients (56.3\%), whereas six (37.5\%) did not show any dilatation. Even in patients with mild MPD stricture and no dilatation at the MPD distal to the stricture, presence of PCIS should be considered. We believe that detailed examination should be performed in such cases. Furthermore, due consideration should be given to the fact that the site of the MPD stricture and cancer as perceived on MRCP and EUS may not necessarily coincide with the pathologically
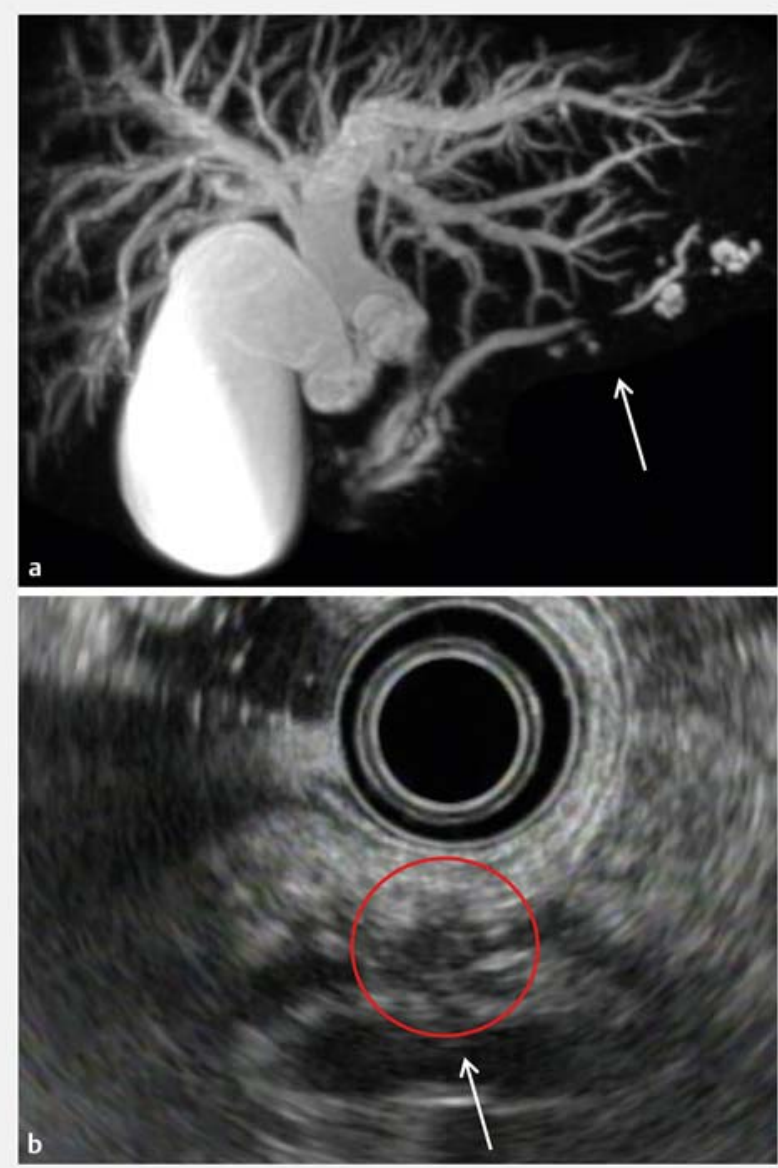

- Fig. 2 Hypoechoic areas in a 66-year-old male with PCIS with cholangiocarcinoma and branch duct IPMN (Case 10). MRCP a and EUS $\mathbf{b}$ revealed MPD stricture (arrow). EUS $\mathbf{b}$ revealed hypoechoic areas surrounding the MPD stricture, which appeared as a hypoechoic mass (red circle). PCIS, pancreatic carcinoma in situ; MRCP, magnetic resonance cholangiopancreatography; EUS, endoscopic ultrasonography; MPD, main pancreatic duct.

confirmed site [21]. There are some cases wherein the observed stricture range is more extensive than the area occupied by the carcinoma; there exist some cases which are contrary [21]. At the Onomichi General Hospital, surgical plans for patients with localized MPD stricture and positive pancreatic juice cytology are prepared, considering the possibility that the cancer may be more extensive than that inferred from the range of the stricture. We make an incision from the margin of the stricture to a distance of approximately $2 \mathrm{~cm}$ distally or proximally, and verify the margin by an intraoperative rapid pathological assessment [21]. Furthermore, concurrent PanIN is commonly found in the resected pancreas. Therefore, from the perspective of multicentric carcinogenesis, rigorous postoperative follow-up observation is recommended in such cases.

Based on comparisons with pathological findings, it was suggested that hypoechoic areas surrounding the MPD stricture on EUS might reflect localized inflammation and fibrosis in the vicinity of the lesion. Regarding the hypoechoic areas, we did not measure them because the boundary with the surrounding 

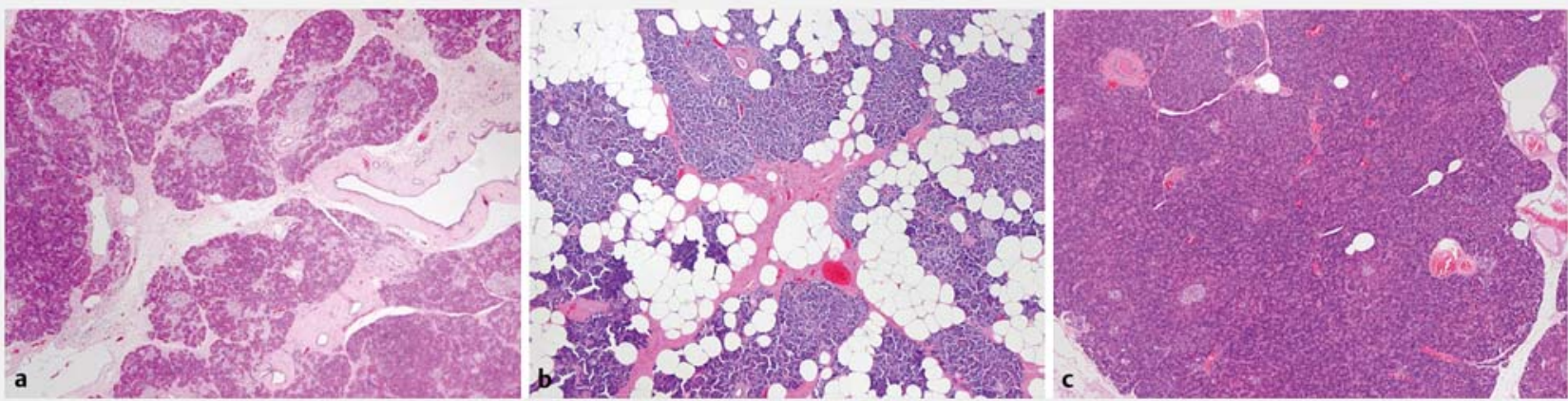

Fig. 3 a Pathological findings of the noncancerous part (proximal to the MPD stricture) in a 73-year-old female with PCIS (Case 8) are consistent with chronic pancreatitis (hematoxylin and eosin, magnification $\times 50$ ). b Findings in a 75-year-old male with PCIS (Case 7 ) reveal severe fatty infiltration in the noncancerous part (hematoxylin and eosin, magnification $\times 50$ ). c Findings in a 59-year-old female with PCIS (Case 13 ) reveal sporadic fat droplets in the noncancerous part, not recognized as chronic pancreatitis (hematoxylin and eosin, magnification $\times 50$ ). MPD, main pancreatic duct; PCIS, pancreatic carcinoma in situ.
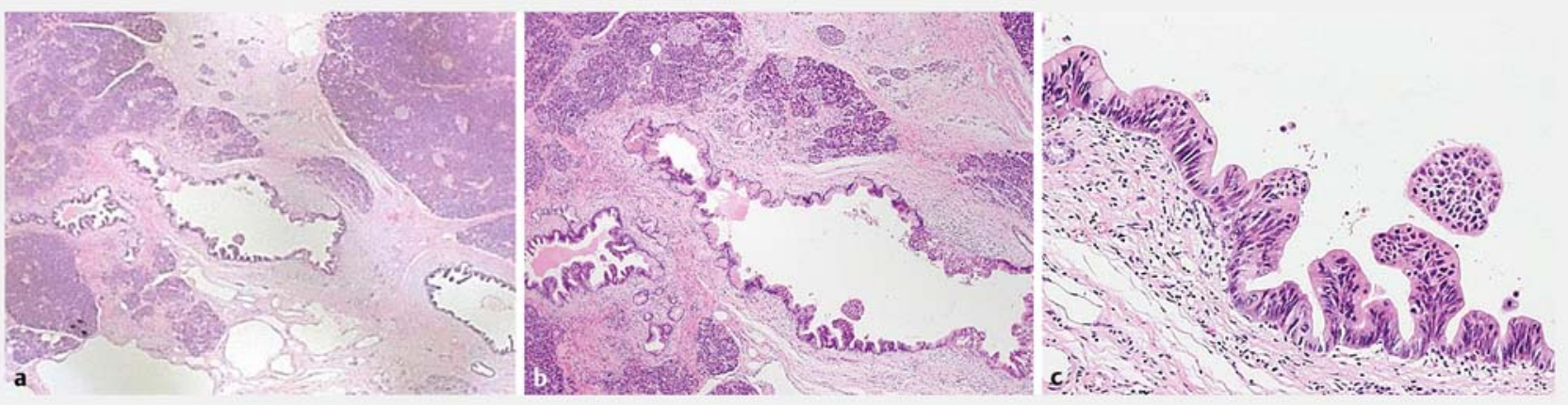

- Fig. 4 Pathological findings surrounding the PCIS in a 59-year-old female with PCIS (Case 13) reveal inflammatory cell infiltration and fibrosis surrounding the PCIS a, b, c hematoxylin and eosin, magnification $\times 12.5, \times 50$, and $\times 200$, respectively. PCIS, pancreatic carcinoma in situ.

pancreatic parenchyma was unclear. Regarding the hypoechoic mass observed in three cases, it was measured because the boundary with the surrounding pancreatic parenchyma was clear. The hypoechoic mass may be drawn due to localized inflammation and fibrosis in the interstitial tissue around the pancreatic ducts in which the PCIS was located, and it is necessary to differentiate it from small invasive ductal carcinoma. When the hypoechoic lesion is depicted surrounding the MPD stricture, if the boundary with the surrounding pancreatic parenchyma is unclear, it is necessary to distinguish the fibrotic area associated with PCIS. Furthermore, if the boundary with the surrounding pancreatic parenchyma is clear, it is necessary to distinguish small invasive ductal carcinoma in addition to PCIS. We also observed that patients without hypoechoic areas surrounding the MPD stricture tend to have less fibrosis and more extensive fatty infiltration ( $\triangleright$ Table 3 ). Although other causes, such as chronic pancreatitis, can result in findings similar to those of pancreatic duct stricture for patients with pathologically proven malignant cells, hypoechoic areas surrounding the MPD stricture are useful markers indicating the presence of cancer. Moreover, such areas, in some cases, were more extensively delineated beyond the range of stenosis.
However, the reliability of using such criteria for cancer diagnosis must be examined in a larger sample of patients.

At the Onomichi General Hospital, when hypoechoic areas are observed surrounding the MPD stricture, we note the possibility of PCIS and proactively perform pancreatic juice cytology multiple times using ERCP and endoscopic nasopancreatic drainage (ENPD). This approach has achieved good diagnostic results [22]. In the event of mass-like delineation, such as that observed in three of our cases, because differentiation between small invasive ductal carcinoma and PCIS is required, performing EUS-FNA is considered initially. However, it is difficult to rule out PCIS even when EUS-FNA results are negative. To differentiate PCIS from invasive ductal carcinoma, careful imaging examination is required. As a diagnostic strategy for MPD stricture, EUS reveals hypoechoic areas with unclear boundary surrounding the MPD stricture, we consider the possibility of PCIS, and perform ERCP (ENPD). When a hypoechoic mass with clear boundary surrounding the MPD stricture is seen on EUS, we consider the possibility of small invasive ductal carcinoma, and perform EUS-FNA. However, even if EUS-FNA results are negative, it does not rule out PCIS, so we also consider ERCP (ENPD). In the future, differential use of ERCP (ENPD) and EUSFNA must be studied further. 
We believe that screening for cases with risk factors for pancreatic cancer is important for early diagnosis of the disease. Chronic pancreatitis, pancreatic fatty infiltration, and IPMN have been reported to be risks factor for pancreatic cancer [23-27]. In this study, histopathological examination of the noncancerous part (proximal to the MPD stricture) revealed characteristic findings of chronic pancreatitis in 13 patients (81.3\%). Histopathological findings of the noncancerous part demonstrated pancreatic fatty infiltration in five patients $(31.3 \%)$. Because pancreatic fatty infiltration is often seen to be scattered in the noncancerous part, its size has not been measured. Based on our examination of the 16 patients with PCIS, it appears that fatty infiltration tends to obviate EUS findings of chronic pancreatitis ( $\triangleright$ Table 3 ). Concurrent IPMN was observed in the resected and residual pancreas in five patients (31.3\%), all of whom had branch duct IPMN. It is necessary to pay attention to occurrence of pancreatic cancer at a site distant from the IPMN. In this study, the two patients who fulfilled the Japanese Clinical Diagnostic Criteria for early chronic pancreatitis [9] were relatively young women who had no history of regular alcohol intake; they did not demonstrate characteristic histological findings of chronic pancreatitis, but only had mild sporadic fat droplets. To clarify the pathological findings and long-term prognosis (progression to chronic pancreatitis and risk of cancer onset) in patients with early chronic pancreatitis, data concerning more cases must be gathered in the future [28].

\section{Conclusions}

We examined the EUS findings from and pathological characteristics of 16 patients with PCIS. PCIS frequently causes localized changes in inflammation and fibrosis around the pancreatic duct. It often accompanies chronic pancreatitis and pancreatic fatty infiltration in the background pancreas. EUS offers sufficient resolution to demonstrate pancreatic changes of PCIS.

\section{Acknowledgements}

Dr. Izumi would like to express his deepest gratitude to Professor Kazuaki Chayama of the Department of Gastroenterology and Metabolism of Hiroshima University, and to Professor Yutaka Sasaki of the Department of Gastroenterology and Hepatology of Kumamoto University for their cooperation in training at Onomichi General Hospital. A part of this report was presented at the 89th Congress of the Japan Gastroenterological Endoscopy Society (Nagoya city, May, 2015).

\section{Competing interests}

\section{None}

\section{References}

[1] Vital Statistics Japan 2013. Cancer deathMinistry of Health, Labor and Welfare; 2013. Available at: http://www.mhlw.go.jp/toukei/saikin/ hw/jinkou/kakutei13/dl/11_h7.pdf] [Accessed November 14, 2017]

[2] Rahib L, Smith BD, Aizenberg R et al. Projecting cancer incidence and deaths to 2030: the unexpected burden of thyroid, liver, and pancreas cancers in the United States. Cancer Res 2014; 74: 2913-2921

[3] Egawa S, Toma H, Ohigashi $\mathrm{H}$ et al. Japan pancreatic cancer registry; 30th year anniversary: Japan Pancreas Society. Pancreas 2012; 41: 985-992

[4] Yamaguchi K, Okusaka T, Shimizu K et al. EBM-based Clinical Guidelines for Pancreatic Cancer (2013) issued by the Japan Pancreas Society: a synopsis. Jpn J Clin Oncol 2014; 44: 883-888

[5] Hanada K, Okazaki A, Hirano N et al. See comment in PubMed Commons below "Diagnostic strategies for early pancreatic cancer". J Gastroenterol 2015; 50: 147-154

[6] Hruban RH, Takaori K, Klimstra DS et al. An illustrated consensus on the classification of pancreatic intraepithelial neoplasia and intraductal papillary mucinous neoplasms. Am J Surg Pathol 2004; 28: $977-$ 987

[7] Basturk O, Hong SM, Wood LD et al. A revised classification system and recommendations from the Baltimore Consensus Meeting for Neoplastic Precursor Lesions in the Pancreas. Am J Surg Pathol 2015; 12: $1730-1741$

[8] Catalano MF, Sahai A, Levy M et al. EUS-based criteria for the diagnosis of chronic pancreatitis: the Rosemont classification. Gastrointest Endosc 2009; 69: 1251 - 1261

[9] The Research Committee of the Intractable Pancreatic Diseases supported by the Ministry of Health, Labor and Welfare of Japan, Japan Pancreas Society, The Japanese Society of Gastroenterology. Japanese clinical diagnostic criteria for chronic pancreatitis 2009. Suizo; 2009; 24: 645-646 [Available at: https://www.jstage.jst.go.jp/article/suizo/24/6/24_6_645/_pdf/-char/en]

[10] Whitcomb DC, Frulloni L, Garg P et al. Chronic pancreatitis: An international draft consensus proposal for a new mechanistic definition. Pancreatology 2016; 16: $218-224$

[11] Sommers SC, Murphy SA, Warren S. Pancreatic duct hyperplasia and cancer. Gastroenterology 1954; 27: 629-640

[12] Hruban RH, Goggins M, Parsons J et al. Progression model for pancreatic cancer. Clin Cancer Res 2000; 6: 2969-2972

[13] Apte MV, Park S, Phillips PA et al. Desmoplastic reaction in pancreatic cancer: role of pancreatic stellate cells. Pancreas 2004; 29: 179-187

[14] Yachida S, Jones S, Bozic I et al. Distant metastasis occurs late during the genetic evolution of pancreatic cancer. Nature 2010; 467: 1114 1117

[15] Del Chiaro M, Verbeke CS, Kartalis N et al. Short-term results of a magnetic resonance imaging-based Swedish screening program for individuals at risk for pancreatic cancer. JAMA Surg 2015; 6: 512 - 518

[16] Harinck F, Konings IC, Kluijt I et al. A multicentre comparative prospective blinded analysis of EUS and MRI for screening of pancreatic cancer in high-risk individuals. Gut 2016; 9: 1505-1513

[17] Canto MI, Hruban RH, Fishman EK et al. Frequent detection of pancreatic lesions in asymptomatic high-risk individuals. Gastroenterology 2012; 4: $796-804$

[18] Verna EC, Hwang C, Stevens PD et al. Pancreatic cancer screening in a prospective cohort of high-risk patients: a comprehensive strategy of imaging and genetics. Clin Cancer Res 2010; 20: 5028-5037

[19] Yasuda I, Iwashita T, Doi S et al. Role of EUS in the early detection of small pancreatic cancer. Dig Endosc 2011; 23: $22-25$ 
[20] Kamata K, Kitano M, Kudo M et al. Value of EUS in early detection of pancreatic ductal adenocarcinomas in patients with intraductal papillary mucinous neoplasms. Endoscopy 2014; 1: $22-29$

[21] Hanada K, Shinzato M, Okazaki A et al. The role and actual practice of EUS in the early diagnosis of pancreatic cancer - Can PCIS be diagnosed? J Tanto to sui 2014; 35: $677-683$

[22] liboshi T, Hanada K, Fukuda T et al. Value of cytodiagnosis using endoscopic nasopancreatic drainage for early diagnosis of pancreatic cancer: establishing a new method for the early detection of PCIS. Pancreas 2012; 41: 523-529

[23] Raimondi S, Lowenfels AB, Morselli-Labate AM et al. Pancreatic cancer in chronic pancreatitis; etiology, incidence, and early detection. Best Prac Res Clin Gastroenterol 2010; 24: 349-358
[24] Tomita Y, Azuma K, Nonaka Y et al. Pancreatic fatty degeneration and fibrosis as predisposing factors for the development of pancreatic ductal adenocarcinoma. Pancreas 2014; 43: 1032 - 1041

[25] Rebours V, Gaujoux S, d'Assignies G et al. Obesity and fatty pancreatic infiltration are risk factors for pancreatic precancerous lesions (PanIN). Clin Cancer Res 2015; 21: 3522 - 3528

[26] Yamaguchi K, Kanemitsu S, Hatori T et al. Pancreatic ductal adenocarcinoma derived from IPMN and pancreatic ductal adenocarcinoma concomitant with IPMN. Pancreas 2011; 40: 571-580

[27] Maguchi H, Tanno S, Mizuno N et al. Natural history of branch duct intraductal papillary mucinous neoplasms of the pancreas: a multicenter study in Japan. Pancreas 2011; 40: 364 - 370

[28] Okazaki A, Hanada K, Ikemoto J et al. The possibility of pancreatic cancer onset based on long-term observation of early-stage chronic pancreatitis. J Tanto to sui 2016; 37: 399-407 